\title{
RAP EM JOÃO PESSOA/PB NA VOZ DE MENESTREIS MC'S: HORIZONTES PARA UMA EDUCAÇÃO EM DIREITOS HUMANOS INTERCULTURAL E EMANCIPATÓRIA
}

\section{RAP IN JOÃO PESSOA/PB IN MENESTREIS MC'S VOICE: HORIZONS FOR EDUCATION IN INTERCULTURAL AND EMANCIPATORY HUMAN RIGHTS}

\author{
${ }^{1}$ Maria Luiza Caxias Albano
}

\section{RESUMO}

Correntes contra-hegemônicas vêm surgindo na reformulação de um discurso clássico de direitos humanos. Assim, a partir da experiência de coletividades periféricas, pretende-se a inserção de novos atores no debate de direitos humanos, bem como a ampliação e reestruturação crítica do que venha a ser sua prática. É nesse cenário que se interpõe o Rap do grupo Menestreis MC's, atuante na cidade de João Pessoa/PB, como forma de ação política e emancipação. Pretende-se observar a contribuição do grupo na possível ressignificação de uma Educação em Direitos Humanos. Utilizou-se, portanto, a revisão bibliográfica e a análise de trechos das letras de música.

Palavras-chave: Rap, Educação em direitos humanos, Intercultural, Contra-hegemonico

\begin{abstract}
Counter-hegemonic currents are emerging in the remake of a classic discourse of human rights. Thus, from the peripheral communities experience, we want to inclusion of new actors in the debate on human rights, as well as the expansion and restructuring of criticism that may be their practice. On this setting stands the Rap MC's Menestréis group acting in João Pessoa/PB, as a form of political action and emancipation. It is intended to observe the group's contribution to possible reinterpretation of a Human Rights Education. It was used, so the literature review and analysis of excerpts from the lyrics.
\end{abstract}

Keywords: Rap, Human rights education, Intercultural, Counter- hegemonic

\footnotetext{
${ }^{1}$ Mestranda em Ciências Jurídicas pela Universidade Federal da Paraíba - UFPB, João Pessoa. Pesquisadora Bolsista CAPES. E-mail: tutortreinamento@gmail.com
} 


\section{INTRODUÇÃO}

A partir da Declaração Universal dos Direitos Humanos de 1948, revigora-se, enquanto discurso uníssono, códigos morais normativos com pretensões universalizantes, reconhecidos atualmente por diversas ideologias ${ }^{1}$ políticas como conteúdo fundamental da ideia de justiça (ATIENZA, 2012, p. 34). No entanto, a materialização desses mesmos direitos não acompanhou essa escalada. Assim, o século XX foi considerado como o mais assassino de que se tem registro, contendo catástrofes humanas que produziram desde as maiores fomes da história, até o genocídio sistemático e a limpeza étnica (DOUZINAS, 2009, p. 20).

Isso porque, o que se firmou hegemonicamente enquanto modelo de direitos humanos está protegido dentro dos próprios limites de sua vinculação histórica ao modo de produção capitalista e ocidental. Ou seja, ainda que essa estrutura socioeconômica tenha permitido a positivação de alguns direitos sociais, que, abstratamente, visam erradicar a miséria e construir uma sociedade livre, igualitária e fraterna, a efetivação desses resta condicionada às contingências e prioridades do mercado global.

A discursividade dos direitos humanos, portanto, é empregada, não raramente, para fins que simbolizam o seu próprio inverso: serve como álibi para intervenções militares "humanitárias" de superpotências ocidentais em países miseráveis e como sacralização da tirania do mercado (ZIZEK, 2010, p. 11). Por outro lado, enquanto perspectiva contrahegemonica de Direitos Humanos ${ }^{2}$, milhões de pessoas e movimentos sociais lutam em defesa de grupos oprimidos, em muitos casos vitimizados por políticas autoritárias, enfrentamentos que frequentemente explícita ou implicitamente são estabelecidos contrariamente ao sistema socioeconômico vigente. (SOUSA SANTOS, 1997, p. 113). Considerando os direitos humanos enquanto um campo de disputas culturais e políticas (VIOLA, 2008, p. 181), fomentam-se discursos e práticas que contribuem para a formação de concepções alternativas ao modelo vigente. Esse horizonte se delineia visando a superação dos paradoxos através da visibilidade de experiências culturais diversas daquela que se concretizou enquanto universal.

A superação do profundo abismo entre teoria e prática nos direitos humanos, a

\footnotetext{
${ }^{1}$ Conforme Slavoj Zizek, sucintamente "pode-se afirmar categoricamente a existência da ideologia qua matriz geradora que regula a relação entre o visível e o invisível, o imaginável e o inimaginável, bem como as relações dessa relação" (ZIZEK, 1996, p. 7).

${ }^{2}$ De acordo com Boaventura de Sousa Santos, "a busca de uma concepção contra-hegemônica dos direitos humanos deve começar por uma hermenêutica de suspeita em relação aos direitos humanos tal como são convencionalmente entendidos e defendidos, isto é, em relação às concepções dos direitos humanos mais diretamente vinculados à matriz liberal e ocidental destes." (SOUSA SANTOS, Boaventura. 2014, p. 16).
} 
necessidade de emancipação de determinados sujeitos desumanizados pelo sistema socioeconomico bem como a existência de lutas identitárias por reconhecimento são pontos levantados pelas perspectivas de direitos humanos insurgentes. É a experiência a favor da construção de uma cultura de direitos humanos, ${ }^{3}$ diferenciando-se do abstracionismo normativo pertencente ao modelo clássico. Assim, empiricamente considerados, os direitos humanos estariam interligados a histórias coletivas que cotidianamente são reconstituídas por meio das experiências culturais que os grupos humanos vivenciam.

Daí o diálogo intercultural ${ }^{4}$ enquanto fio condutor para despertar o senso de humanidade: como os direitos humanos não estão no mundo das ideias, sendo resultantes de vivências intersubjetivas, é preciso falar em uma linguagem que seja organizada em sentidos locais, mutuamente inteligíveis, e que se constitua em rede de referências normativas capacitantes. (SOUSA SANTOS, 1997, p 115). O intuito é de fazer reconhecer "o outro" - o diferente - enquanto humano sem falar em uma moral universalizante, mas fomentando o protagonismo dos próprios sujeitos de direito.

Para tanto, a educação em direitos humanos ${ }^{5}$ poderá se mostrar enquanto uma importante ferramenta na promoção dessas perspectivas insurgentes. Ora, considerando educar um ato de formação de consciência - com conhecimentos, com valores, com

\footnotetext{
${ }^{3}$ Cultura de Direitos Humanos apresentada no presente trabalho está associada àquela referida por Vera Maria Candau, ou seja, "uma cultura dos Direitos Humanos que penetre todas as práticas sociais e seja capaz de favorecer processos de democratização, de articular a afirmação dos direitos fundamentais de cada pessoa e grupo sociocultural, de modo especial os direitos sociais e econômicos, com o reconhecimento dos direitos à diferença." (CANDAU, 2007, p. 399)

${ }^{4} \mathrm{O}$ diálogo intercultural está relacionado com o rompimento de uma visão essencialista das culturas e das identidades culturais. Nesse sentido, e sobre o diálogo intercultural, Vera Maria Candau “(...) concebe as culturas em contínuo processo de elaboração, de construção e reconstrução. Certamente cada cultura tem suas raízes, mas essas raízes são históricas e dinâmicas. Não fixam as pessoas em determinado padrão cultural.". A mesma autora considera ainda que "(...) nas sociedades em que vivemos os processos de hibridização cultural são intensos e mobilizadores da construção de identidades abertas, em construção permanente, o que supõe que as culturas não são puras. Sempre que a humanidade pretendeu promover a pureza cultural e étnica, as consequiências foram trágicas: genocídio, holocausto, eliminação e negação do outro. A hibridização cultural é um elemento importante para levar em consideração na dinâmica dos diferentes grupos socioculturais. A consciência dos mecanismos de poder que permeiam as relações culturais constitui outra característica dessa perspectiva. As relações culturais não são relações idílicas, não são relações românticas; estão construídas na história e, portanto, estão atravessadas por questões de poder, por relações fortemente hierarquizadas, marcadas pelo preconceito e pela discriminação de determinados grupos." (CANDAU, 2008, p.51).

${ }^{5}$ Para Vera Maria Candau, o termo "educação em direitos humanos" é reconhecidamente polissêmico: Em relação à polissemia da expressão educação em direitos humanos, os pesquisadores afirmaram a importância de não se deixar que esta expressão seja substituída por outras consideradas mais fáceis de serem assumidas por um público amplo, como educação cívica ou educação democrática, ou que restrinjam a educação em direitos humanos a uma educação em valores, inibindo seu caráter político. (CANDAU, 2009, p. 70).
} 
capacidade de compreensão, a educação em direitos humanos tem a potencialidade de fazer com que sujeitos assumam a compreensão do mundo, de si mesmo, da inter-relação entre os dois, protagonizando suas próprias histórias (SADER, 2007, p. 80).

Desse modo, trata-se de uma educação especificamente não formal: as concepções insurgentes/alternativas de direitos humanos exigem também uma educação intercultural. Nesse sentido, o viés intercultural pretende abarcar o reconhecimento do "outro" como forma de fomentar o diálogo entre os diferentes grupos sociais e culturais, enfrentando o conflito gerado pela assimetria de poder entre as diversas coletividades e favorecendo a construção de um projeto comum, onde as diferenças sejam integradas (CANDAU, 2008, p.52).

Nesse contexto, insere-se a produção artística de Rap na cidade de João Pessoa/PB, mais especificamente referente ao grupo Menestréis MC's, como energia mobilizadora de grupos sociais historicamente marginalizados, formando uma rede identitária de consciência e resistência às problemáticas impostas pelo modelo socioeconômico vigente. O que se pretende é correlacionar a construção artística do grupo de Rap Menestréis MC's com a necessária e devida educação em direitos humanos sob um viés intercultural e emancipador, a partir dos marcadores de classe e raça. Para tanto, foram utilizados os recursos da pesquisa e revisão bibliográfica, a análise das letras das músicas, bem como a observação e interação com o grupo Menestréis MC's em sua atuação diária.

\section{O RAP ENQUANTO ENERGIA MOBILIZADORA DE COMUNIDADES PERIFÉRICAS: ATUAÇÃO DO GRUPO MENESTREIS MC'S NA CIDADE DE JOÃO PESSOA-PB}

Aqui o favelado com certeza vai aplaudir Tenho esperança por isso vou prosseguindo Fica ligado que o rap ta invadindo É a pancada que vai estourar seus timpanos Aqui é o Menestreis em nome dos oprimido

(Menestreis MC's)

O Rap se constituiu historicamente enquanto vertente poético musical que compõem o Hip Hop, associando-se e interagindo com o Grafite, a expressão plástica e o Break, a modalidade cênica, dança característica (ALVES, 2008, p. 27). Surgido no final da década de 60 em Nova York, o Hip Hop aparece enquanto a junção entre ritmos trazidos da Jamaica e manifestações artísticas dos subúrbios estadunidenses como forma de protesto: grita-se através da arte a situação de exclusão social. (ROCHA; DOMENICH; CAETANO, 2001, p. 
9). Assim, o Rap traz em seu bojo uma contracultura nascida entre os grupos sociais historicamente marginalizados, sendo um espaço de construção política onde as contradições e opressões de uma vida urbana emergem.

No Brasil, o Rap tem início a partir dos Breaks presentes na cidade de São Paulo na década de 80. Não à toa o Hip Hop encontrou nas grandes capitais do país o início de sua difusão: os altos índices de desigualdade e exclusão social construíram um terreno fértil para a incitação dessa forma de resistência cultural. Em João Pessoa, o movimento Hip Hop também tem o ponta pé inicial a partir da década de 80, tendo a proliferação de grupos de Rap ocorrido apenas a partir da década de 90 (ALVES, 2008, p. 21). É interessante ressaltar que apesar do Hip Hop ter sido formatado na periferia norte-americana, o mesmo assume aspectos específicos e regionais a depender de onde será desenvolvido, sem perder o caráter de denúncia social.

Nesse contexto, o grupo Menestreis MC's, formado pelos MC's Daniel Atalaia, 23 anos; Peter Fé, 20 anos e Edgar Silva, 25 anos, protagoniza a cena rapper pessoense juntamente com outros grupos de rappers que surgem a partir de bases socioculturais semelhantes: a) fazer frente à indústria cultural hegemônica; b) resistir às opressões de raça e classe visibilizando realidades de comunidades periféricas e c) possibilitar a politização de grupos historicamente marginalizados através do Rap, criando um plexo de simbologias e identidades que interligam sujeitos submetidos às mesmas condições materiais. Evidentemente, as finalidades dos grupos de rappers na cidade de João Pessoa não se limitam às elencadas nesse trabalho, porém, por questões metodológicas, os três aspectos estabelecidos acima são categorizados a fim de analisa-los mais pormenorizadamente.

\subsection{O Rap como Contracultura: Menestréis MC's, Poetas Marginais.}

Eu tenho a ideologia que vem da favela Minha mente não é influenciada pela tela

(Menestreis MC's)

O nome do grupo de Rap Menestreis MC's simboliza a origem periférica dessa formação. Assim, o termo "Menestreis" vem da ideia de "poeta marginal", "poeta de rua", que assim figurava em tempos feudais. É essa a identidade que o grupo assume ao se colocar como aquele que canta a amargura da vida.

Demonstra-se, desde já, que a referida formação de rappers se identifica como voz oriunda da periferia pessoense, e que, portanto, faz emergir subjetividades até então ignoradas 
pelo sistema mercadológico cultural ${ }^{6}$. A respeito do controle de subjetividades por meio da cultura hegemônica, Felix Guattari afirma:

O que caracteriza os modos de produção capitalísticos é que eles não funcionam unicamente no registro dos valores de troca, valores que são da ordem do capital, das semióticas monetárias ou dos modos de financiamento. Eles funcionam também através de um modo de controle da subjetivação, que eu chamaria de "cultura de equivalência" ou de "sistemas de equivalência na esfera da cultura". Desse ponto de vista o capital funciona de modo complementar à cultura enquanto conceito de equivalência: o capital se ocupa da sujeição econômica, e a cultura, da sujeição subjetiva. (GUATTARI e ROLNIK, 2013, p. 21)

Considerando a subjugação de subjetividades pela cultura capitalística, é importante destacar que o principal cenário do desenvolvimento do Rap, o espaço urbano, configura-se enquanto palco de conflitos sociais: de um lado, existe o controle do acesso aos recursos por financistas, empreiteiros e grandes grupos econômicos para fins exclusivos de acumulação do capital (HARVEY, 2014, p. 97); do outro, grupos excluídos dessa sistematização que reivindicam espaço de poder político equitativo. Daí a existência de núcleos de resistência, traduzidos muitas vezes em comunidades inseridas na própria cidade, que desenvolvem experiências de contracultura em relação àquela imposta pelo modelo hegemônico.

Desse modo, o Rap em João Pessoa se constitui enquanto uma rede identitária, que se desenvolve através da compreensão do local - periferias - como espaço de vivências emocionais e coletivas, depositário de memórias e tradições bem como de contestação do modelo socioeconômico excludente. Portanto, as letras das músicas são elaboradas a partir das vidas dos próprios rappers enquanto expressão artística de suas próprias vivências.

Tais experiências fazem contraponto àquelas dos espaços genéricos, consumeristas em sua essência, impessoais, anônimos, difusos e padronizados, que não apenas se esquivam a assumir identidade própria, como tendem a dissolver a de seus usuários, aniquilando singularidades (SANTOS, 2006, p. 13). O Rap pessoense, portanto, representado pelo grupo Menestreis MC's, realiza o papel de forjar uma contracultura, que surge em resposta aos problemas em comum enfrentados por coletividades periféricas na medida em que são

\footnotetext{
${ }^{6}$ Howard S. Becker, analisando a questão dos músicos de casas noturnas enquanto grupo artístico marginalizado considera que "pessoas que se envolvem em atividades consideradas desviantes enfrentam tipicamente o problema de que sua concepção a respeito do que fazem não é partilhada por outros membros da sociedade. (...) Como operam dentro da cultura da sociedade mais ampla, porém diferentemente dela, essas culturas são muitas vezes chamadas de subculturas" (BECKER, 2008, p. 90-91).
} 
capazes de interagir e se identificar entre si enquanto parte daquele determinado contexto (BECKER, 2008, p. 90).

Assim, ainda que exista um controle de subjetivações por meio da cultura capitalística, a qual se apresenta enquanto forma hegemônica e monolítica, não se pode olvidar de coletividades que não só resistem, mas também reagem a essa imposição. Nesse aspecto, Rosa Maria Godoy Silveira expõe que "o outro"7 nunca deixou de emitir sinais (discursos) de sua existência durante toda a História, ainda que não alcançassem amplificações devido à disparidade em relação aos meios de comunicação e potência frente ao cultural hegemônico. Conclui a mesma autora que "o mesmo processo que engendra o domínio capitalista, engendra o seu avesso" e "este cotejo é o que engendra a luta contra- hegemônica." (SILVEIRA, 2007, p. 259).

Daí o sentido em utilizar o termo "contracultura” em oposição/diferenciação à "cultura hegemônica", "cultura capitalística", "cultura monolítica", uma vez que há, através de nichos de experiências marginalizadas, a existência de discursos que protestam em relação às condições periféricas. Tem-se, portanto, a disputa por condições humanas, valendo-se das diferenças culturais como argumento e ação de reivindicação na esfera pública (SILVEIRA, 2007, p. 262), transformando o exercício de contracultura em um instrumento para alargar a esfera daquilo que se compreendeu historicamente enquanto "dignidade humana"

Resta observar que para além daquilo já exposto anteriormente, a contracultura do Hip Hop, em especial o Rap desenvolvido pelo grupo Menestreis MC's, desempenha a função de quebrar com o silêncio, o qual Boaventura de Sousa Santos explica resultar dos processos de colonialismo/colonialidade:

\footnotetext{
7 O "Outro" está colocado aqui no sentido de figurar em um polo distinto daquele que foi consagrado/normatizado como o "Homem" das declarações de Direitos Humanos modernas, iniciadas a partir das revoluções burguesas. Assim, qualquer característica que desvie do "Homem", heterossexual, branco, colonizador, inserido em uma cultura eurocêntrica, ocidental e capitalista, pode ser considerado enquanto "o outro" - o diferente e/ou marginalizado.

${ }^{8}$ A concepção de "dignidade humana" está vinculada às bases de Direitos Humanos liberais, sendo utilizada com frequência de forma retórica. Quanto à vagueza do termo, Rodrigo Kaufmann em sua tese esclarece: "Dizer que o 'sistema jurídico' precisa respeitar a dignidade da pessoa humana não significa dizer nada, assim como dizer que determinada lei é proporcional se lida sob a óptica dos direitos humanos também pouco significado tem. Não são expressões que expõem pontos-de-vista, que fazem transparecer interesses políticos contrapostos, que apresentam tolerância ou ódio, que se relacionam com a história de dor e de sofrimento de pessoas concretas. São expressões tão vagas, imprecisas, obsoletas e inúteis como discutir, até a filigrana, quais serão os termos de nossa convenção linguística para falarmos como ciência." (KAUFMANN, 2010, p. 207-208). Por isso a necessidade de preencher com aspectos concretos, a partir das experiências, tal conceito, que contemporaneamente tem um alto grau de abstracionismo.
} 
O silêncio é o resultado do silenciamento: a cultura ocidental e a modernidade têm uma ampla experiência histórica de contato com outras culturas, mas foi um contato colonial, um contato de desprezo, e por isso silenciaram muitas dessas culturas, algumas das quais destruíram. Por isso, quando queremos tentar um novo discurso ou teoria intercultural, enfrentamos um problema: há nos oprimidos aspirações que não são proferíveis, porque foram consideradas improferíveis depois de séculos de opressão. (SOUSA SANTOS, 2007, p. 55).

Desse modo, reconhece-se o enorme desafio em fazer quebrar o silêncio por parte de grupos excluídos do sistema socioeconômico. Destaca-se ainda que a exclusão social vem funcionando contemporaneamente enquanto um dos processos de "desumanização". Nesse sentido, Luciano Oliveira afirma:

Dois traços - além, evidentemente, da não-inserção no mundo normal do trabalho -, ambos inter-relacionados, seriam específicos dessa forma contemporânea de exclusão. O primeiro é que os excluídos, por seu crescimento numérico e por não possuírem as habilidades requeridas para ser absorvidos pelos novos processos produtivos - já em si liberadores de mãode-obra - teriam se tornado 'desnecessários economicamente'. (...) o fato é que os excluídos, aparentemente postos à margem do processo produtivo e do circuito econômico tradicional, são no momento considerados "desnecessários". Mas não apenas isso. O segundo traço, aquele que mais imprime força e sentido à própria ideia de exclusão, tem a ver com o fato de que sobre eles se abate um estigma, cuja consequência mais dramática seria a sua expulsão da própria 'órbita da humanidade', isso na medida em que os excluídos, levando muitas vezes uma vida considerada subumana em relação aos padrões normais de sociabilidade, "passam a ser percebidos como indivíduos socialmente ameaçantes e, por isso mesmo, passíveis de serem eliminados'.”. (OLIVEIRA, 1997, p. 51)

Logo, o discurso de direitos humanos que se coloca contrário à exclusão social, mas que ao mesmo tempo permanece de forma abstrata, apenas em teoria, utilizando uma gramática artificialmente universalizante e totalizante, não atua a ponto de enfrentar a desestruturação dessas formas desumanizantes na sociedade contemporânea ocidental. Por isso a necessidade não só de valorizar o desenvolvimento da contracultura, como também de buscar uma construção gramatical de direitos humanos que seja reflexo desses processos de contra-hegemonia. Afinal, é através desses movimentos contraculturais que o protagonismo de sujeitos até então invisibilizados, dentro de contextos opressores, passa a se constituir enquanto luta reivindicatória em um plano concreto. 


\title{
2.2 O Rap como Resistência às Opressões de Classe e Raça: Menestreis MC's e a Denuncia de um Cotidiano Permeado por Opressões.
}

\author{
Aqui em jampa a a parada ta sinistra, \\ Ou você enfrenta a morte, ou a morte arrasta sua vida \\ Não abaixa a cabeça \\ Mantenha ela erguida \\ Tem que ter humildade também muita malicia \\ Saca as esquinas como tem \\ Traficante, drogado só no vai e vem \\ Daqui pro fim do ano muitos vão pro alem
}

(Menestreis MC's)

A cidade de João Pessoa figurou como uma das capitais do país mais violentas para jovens negros. O número foi constatado pelo Mapa da Violência 2014 (WAISELFISZ, 2014): em 2012 foram mortos 358 negros e 12 brancos, o que demonstra uma seletividade social dos que irão ser assassinados. O extermínio da juventude negra é um dos problemas enfrentados pela capital paraibana. Nesse contexto, o grupo de Rap Menestreis MC's, através de suas letras, expõe a realidade de segregação racial e classista a qual a juventude da periferia pessoense está submetida.

É importante destacar que os dados relativos à cidade de João Pessoa se reproduzem em maior ou menor escala como padrões nacionais, ou seja, o extermínio da juventude negra não é um caso isolado dentro do panorama de cidades brasileiras. Isso porque, apesar do mito da democracia racial $^{10}$, vive-se em um país de racismo permanente, constatado a partir de vivências e dados estatísticos. A juventude negra, ao ser marginalizada e segregada, não tem oportunidade de acesso a esferas de poder sistematizadas dentro da lógica capitalista e colonialista. Nesse contexto, insere-se a questão da criminalidade, muito bem delimitada por

\footnotetext{
${ }^{9}$ Redução do nome da cidade de João Pessoa, gíria popular.

${ }^{10}$ Sobre o termo, Antonio Sergio A. Guimarães afirma: "Na sociologia moderna, Gilberto Freyre foi o primeiro a retomar a velha utopia do paraíso racial, cara ao senso comum dos abolicionistas, dando-lhe uma roupagem científica. (...) Sem ter cunhado a expressão, e mesmo avesso a ela, já que evocava uma contradição em seus termos (as raças são grupos de descendência e portanto fechados, ao contrário da democracia que ele pregava), mas grandemente responsável pela legitimação científica da afirmação da inexistência de preconceitos e discriminações raciais no Brasil, Freyre mantém-se relativamente longe da discussão enquanto a idéia de uma 'democracia racial' permanece relativamente consensual, seja como tendência, seja como padrão ideal de relação entre as raças no Brasil. Quando, entretanto, a situação polariza-se na África, com as guerras de libertação, e no Brasil, com o avanço ideológico da 'negritude' e do movimento pelas reformas sociais, Freyre vai louvar a 'democracia racial' ou 'étnica' como prova da excelência da cultura luso-tropical. Ironicamente, tratará a 'negritude' como um mito racial (ou uma mística)". (GUIMARÃES, 2001, p. 152-154). Assim, o termo "democracia racial" foi usualmente veiculado como forma de encobrir a existência de preconceitos raciais na sociedade brasileira.
} 
Terlúcia Silva, coordenadora da ONG Bombidelê que atua na cidade de João Pessoa, referência em questões raciais:

Sentimos falta de políticas preventivas, porque as repressivas também matam. É muito fácil ver um dado desse e dizer que a vítima tinha envolvimento com o tráfico, mas o que leva a juventude em massa a se envolver com o tráfico? A culpa não é da droga, é a falta de política contra esse problema, colocando os negros mais vulneráveis (TERLUCIA SILVA, 2014).

O Hip Hop, como exposto anteriormente, nasceu nas periferias novaiorquinas entre "suburbanos", o que, dentro de um recorte social, atinge grupos historicamente marginalizados, quais sejam, negros e imigrantes caribenhos. Dessa forma, o Rap sempre teve uma interligação estreita com o Movimento Negro: é uma das expressões artísticas de uma política identitária que se autoafirma enquanto forma de empoderamento de sujeitos subordinados a uma lógica segregacionista. Compreender o porquê do preconceito racial e da subjugação classista na sociedade contemporânea torna-se fundamental na formulação da resistência negra.

Não distintamente, na realidade periférica de João Pessoa, cidade em que o extermínio da juventude negra se concretiza a partir de números alarmantes, o Rap tem se desenvolvido com a finalidade de denunciar um cotidiano permeado pelo preconceito racial e exclusão social. Assim, o grupo Menestreis MC's se identifica com a questão étnica: pertencentes a famílias negras, consideram-se como difusores de sentimentos e experiências que a juventude negra vivencia em sua realidade cotidiana. Reconhecem, dessa forma, que o Rap fora parte fundamental para a tomada de consciência quanto ao espaço que ocupam socialmente.

Destaca-se que as questões relacionadas às opressões de raça estão interseccionalizadas às opressões de classe, ou seja, o racismo é um dispositivo que combina desigualdade e exclusão. Nos termos de Boaventura de Sousa Santos, esses dois sistemas, a desigualdade e a exclusão, são de pertença hierarquizada:

No sistema de desigualdade, a pertença dá-se pela integração subordinada enquanto que no sistema de exclusão dá-se pela exclusão. A desigualdade implica um sistema hierárquico de integração social. Quem está em baixo está dentro e sua presença é indispensável. Ao contrário, a exclusão assenta num sistema igualmente hierárquico, mas dominado pelo princípio da segregação: pertence-se pela forma como é excluído. Quem está em baixo, está fora. (SOUSA SANTOS, Boaventura, 2010, p. 280). 
Desse modo, o sistema de desigualdade estaria associado à relação capital/trabalho, uma desigualdade classista baseada na exploração, enquanto que o sistema de exclusão estaria associado a um processo histórico por meio do qual uma cultura sobrepõe a outra, sob a forma de dominação. As questões levantadas nas letras dos Menestreis MC's retratam bem a transversalidade desses dois sistemas, funcionando como gramática alternativa de "dignidade humana". É nesse contexto que, caso se considere uma polissemia do termo "Direitos Humanos" ou da educação a esse campo direcionada (CANDAU, 2007, p. 403), certamente não poderá haver a supressão de linguagens emancipatórias que retratem esses dois sistemas, como expressas nas letras de Rap dos Menestréis MC's.

\subsection{Politização e Educação: Menestreis MC's e a Contribuição na Tomada de}

Consciência em Comunidades Periféricas da Cidade de João Pessoa - PB

O que ta errado é tu deixar se levar, .Pelo que o sistema quer implantar,

A manipular, te alienar

Para mais na frente, lhe ultrajar

(Menestreis MC's)

A atuação do grupo Menestreis MC's não se restringe ao espaço de produção artística: considerando a construção do Rap enquanto um ato político, a arte dos rappers se imiscui em lutas que se concretizam no espaço urbano, ao que se pode constatar no videoclip "Atitude Ilegal", gravado na ocupação "Tijolinho Vermelho"11 em João Pessoa, e em movimentos de militância social, como a participação na "Marcha da Maconha de João Pessoa, 2015"12. Cria-se, assim, não só uma mera produção artística como também um espectro de politização que envolve todo o microcosmo relacionado a essa contracultura.

Através dessa rede de interligações, e no desempenho da prática juntamente com a experiência do cotidiano de comunidades periféricas, os rappers do Menestreis MC's

${ }^{11}$ O "Tijolinho Vermelho" é uma ocupação urbana realizada por mais de 200 famílias a um prédio, abandonado há cerca de 20 anos, na área central da cidade de João Pessoa, o antigo Hotel Tropicana. De acordo com o movimento Terra Livre, que trata de questões urbanas na capital paraibana, essas pessoas ocuparam o local por falta de alternativas de moradia. "há anos [essas famílias] aguardam nas ruas, em casas alugadas a elevados preços, ou em áreas de risco, serem contempladas por programas habitacionais, estes insuficientes para a grande demanda habitacional do país", informou em nota o movimento. (TIJOLINHO VERMELHO, 2015)

12 A Marcha da Maconha é um movimento organizado nacionalmente, e tem por pauta central o antiproibicionismo e a descriminalização do tráfico de drogas, compreendendo ser a "guerra às drogas" uma guerra direcionada contra a juventude negra e periférica. 
realizam aquilo que Paulo Freire denominou de "conscientização". Segundo o pedagogo de viés marxista, "a conscientização é um esforço através do qual, ao analisar a prática que realizamos, percebemos em termos críticos o próprio condicionamento a que estamos submetidos" (FREIRE, 1977, p. 85). Nesse sentido, o desenvolvimento contracultural do Rap enquanto ação política desenvolve a tomada de consciência (conscientização) não só daqueles que estão na promoção artística diretamente vinculados, no caso os rappers do Menestreis MC's, como também de todos que experienciam as opressões interseccionadas em nichos socialmente marginalizados. Há o estímulo, através da contracultura do Hip Hop, e, portanto, de uma educação libertadora, para que coletividades ultrajadas pelo sistema socioeconômico imperante tomem para si a possibilidade de transformação do mundo ao seu redor e de sua própria condição de existência.

Sobre educação libertadora, e ainda na linha de pensamento paulofreiriano, essa se distinguiria da educação "domesticadora". Dentro dessa perspectiva, a educação "domesticadora" tem como conotação central a dimensão manipuladora nas relações, havendo uma dicotomia entre quem manipula e quem é manipulado, por outro lado, a educação libertadora é o processo no qual há a predominância de princípios horizontais, ou seja, o educador convida os educandos a conhecer, a desvelar a realidade, de modo crítico (FREIRE, 1977, p. 89). Tendo por superada a rígida bipolaridade educador-educando, o papel do Rap pessoense, em especial do grupo Menestreis MC's, ao fomentar o senso crítico em comunidades marginalizas, é de proporcionar uma educação que liberta e transforma.

Vale destacar que o desempenho do Rap pessoense como força educadora não poderá ser considerada "inferior" por essa via não constituir um meio formal e institucionalizado de educação. Quanto a essa questão e seguindo também pelo viés marxista, István Mészáros chama atenção para o papel limitado que a educação institucionalizada/formal vem desempenhando na sociedade capitalista:

Uma das funções principais da educação formal nas nossas sociedades é produzir tanta conformidade ou "consenso" quanto for capaz, a partir de dentro e por meio dos seus próprios limites institucionalizados e legalmente sancionados. Esperar da sociedade mercantilizada uma sanção ativa - ou mesmo mera tolerância - de um mandato que estimule as instituições de educação formal a abraçar plenamente a grande tarefa histórica do nosso tempo, ou seja, a tarefa de romper com a lógica do capital no interesse da sobrevivência humana, seria um milagre monumental. (MÉSZARÓS, 2008, p. 45).

Nesses termos, não há como desqualificar a educação "informal”, que acontece por meio de contraculturas, enquanto energia que propicia a conscientização e transformação. 
Arrisca-se a afirmar, inclusive, e diante do citado, que os meios artísticos de contracultura são necessários para a quebra do paradigma de uma educação formal "domesticadora”. É nesse sentindo também que não convém falar na educação em Direitos Humanos sem considerar tanto os preceitos de uma educação libertadora quanto as perspectivas de contracultura emergentes em comunidades periféricas.

Ora, considerando as correntes insurgentes que pretendem ir além de uma conceituação liberal de Direitos Humanos, o que se espera nessa área é justamente o despertar de um senso crítico aguçado. Conscientizar-se do papel que assume no sistema socioeconômico imperante é escrever a própria história de sua condição humana, é preencher o conceito abstrato de "dignidade humana" com questões que se materializam na prática. Assim, considerando o campo dos Direitos Humanos como permeado por processos de permanente gestação, provocados por reivindicações e conflitos, a educação nessa área deverá possibilitar a emergência de novos atores sociais na construção desses saberes (WOLKMER, 2010, p. 25). Por isso a relevância do Rap na cidade de João Pessoa enquanto prática educativa não formal em Direitos Humanos.

\section{CONCLUSÃO}

Diante do exposto, percebe-se que a produção artística de Rap na cidade de João Pessoa/PB, mais especificamente referente ao grupo MC's Menestréis, funciona como energia mobilizadora de grupos sociais historicamente marginalizados, formando uma rede identitária de consciência e resistência às problemáticas impostas pelo modelo socioeconômico vigente. Assim, ao a) fazer frente à indústria cultural hegemônica; b) resistir às opressões de raça e classe visibilizando realidades de comunidades periféricas e c) possibilitar a politização de grupos historicamente marginalizados através do Rap, criando um plexo de simbologias e identidades que interligam sujeitos submetidos às mesmas condições materiais; o grupo de rappers contribui para a formação de espaços que materializam aquilo que correntes contra hegemônicas de Direitos Humanos levantam.

Apesar de se reconhecer o enorme desafio em quebrar o silêncio por parte de grupos excluídos do sistema socioeconômico, observa-se que o movimento de contracultura construído pelo grupo Menestreis MC's funciona como onda difusora de ideários advindos da periferia. Isso favorece a construção da educação em Direitos Humanos a partir do protagonismo de sujeitos até então marginalizados. Nesse sentido, existem espaços para que a partir das rupturas encontradas no discurso universalizante de direitos humanos haja uma 
reformulação das Teorias que baseiam categorias como “dignidade humana”, por exemplo. É também um viés de construção de parâmetros insurgentes dentro das Teorias de Direitos Humanos.

Conclui-se, assim, que a atuação do grupo de rapper Menestreis MC's abarca as três dimensões consideradas por Vera Maria Candau enquanto necessárias para uma Educação em Direitos Humanos na América Latina, quais sejam: 1) a formação de sujeitos de direitos; 2) o favorecimento de processos de "empoderamento" ao trabalhar na perspectiva do reconhecimento e valorização dos grupos sócio-culturais excluídos e discriminados, favorecendo sua organização e participação ativa na sociedade civil e 3) a observância de processos de transformação necessários para a construção de sociedades verdadeiramente democráticas e humanas. (CANDAU, 2009, p. 65-82)

\section{REFERENCIAS}

ALVES, Valmir Alcântara. De repente o Rap na educação do negro: o Rap do movimento Hip-Hop nordestino como Prática Educativa da Juventude Negra. Dissertação (Mestrado em Educação), Universidade Federal da Paraíba, João Pessoa, 2008.

ATIENZA, Manuel. Marxismos y Derechos Humanos. In: FEITOSA, Enoque;

BECKER, Howard Saul. Outsiders: estudos de sociologia do desvio. Tradução: Maria Luiza X. de Borges; $1^{\text {a }}$ Ed. Rio de Janeiro: Jorge Zahar, 2008.

CANDAU, Vera Maria. Educação em direitos humanos: desafios atuais. In: SILVEIRA, Rosa Maria Godoy (Orgs.). Educação em Direitos Humanos: fundamentos teóricometodológicos. João Pessoa: Editora Universitária da UFPB, 2007.

. Direitos Humanos, educação e interculturalidade: as tensões entre igualdade e diferença. In: Revista Brasileira de Educação, v. 13, n. 37 jan./abr., 2008.

. Educação em Direitos Humanos e diferenças culturais: questões e buscas. In: Revista Múltiplas Leituras, v.2, n. 1, p. 65-82, jan. / jun. 2009

DOUZINAS, Costas. O fim dos Direitos Humanos. São Leopoldo: Unisinos, 2009.

FREIRE, Paulo. Ação Cultural para a liberdade. 2a ed. Rio de Janeiro: Paz e terra, 1977.

FREITAS, Lorena. (Orgs.). Marxismo, Realismo e Direitos Humanos. João Pessoa: Editora Universitária da UFPB, 2012. 
GUATTARI, Felix; ROLNIK, Suely Rolnik. Micropolitica: cartografias do desejo. 12a Ed. Petrópolis: Vozes, 2013.

GUIMARÃES, Antonio Sérgio A. Democracia Racial: o ideal, o pacto, o mito. In: Revistas Novos Estudos CEBRAP, n. 61, p. 147-162, nov., 2001.

HARVEY, David. Cidades Rebeldes: do direito à cidade à revolução urbana. São Paulo: Martins Fontes, 2014.

KAUFMANN, Rodrigo de Oliveira. Direitos Humanos, Direito Constitucional e Neopragmatismo. Tese (Doutorado em Direito) - Faculdade de Direito, Universidade de Brasília, Brasília, 2010.

MÉSZÁROS, István. A educação para além do capital. Tradução: Isa Tavares. São Paulo: Boitempo, 2008.

OLIVEIRA, Luciano. Os Excluídos Existem? Notas sobre a elaboração de um novo conceito. In: Revista Brasileira de Ciências Sociais, n. 33, fev. 1997, p. 49-61.

ROCHA, Janaina; DOMENICH, Mirella; CAETANO, Patrícia. Hip Hop, a periferia grita. São Paulo: Fundação Perseu Abramo, 2001.

SADER, Emir. Contexto histórico e educação em direitos humanos no Brasil: da ditadura à atualidade. In: SILVEIRA, Rosa Maria Godoy (Orgs.). Educação em Direitos Humanos: fundamentos teórico-metodológicos. João Pessoa: Editora Universitária da UFPB, 2007.

SANTOS, Carlos Ferreira José dos. Identidade urbana e globalização: a formação dos múltiplos territórios em Guarulhos-SP. São Paulo: Annablume; Guarulhos: Sindicato dos professores de Guarulhos, 2006.

SILVA, Terlucia. Disponível em: < http://g1.globo.com/pb/paraiba/noticia/2014/07/joao-pessoa-ecapital-com-maior-taxa-de-homicidios-de-negros-no-pais.html>, acesso em: 07 de jul. de 2015.

SILVEIRA, Rosa Maria Godoy. Educação em/para os direitos humanos: entre a universalidade e as particularidades, uma perspectiva histórica. In: SILVEIRA, Rosa Maria Godoy (Orgs.). Educação em Direitos Humanos: fundamentos teórico-metodológicos. João Pessoa: Editora Universitária da UFPB, 2007.

SOUSA SANTOS, Boaventura. A Gramática do Tempo: para uma nova cultura política. $3^{\mathrm{a}}$ ed. São Paulo: Cortez. 2010.

. Renovar a teoria critica e reinventar a emancipação social. Tradução: Mouzar Benedito. São Paulo: Boitempo, 2007.

. Se Deus fosse um ativista dos Direitos Humanos. $2^{\text {a }}$ Ed. São Paulo: Cortez,

2014. 
. Uma Concepção Multicultura de Direitos Humanos. In: Revista Lua Nova,

n. 39, São Paulo, 1997, p. 107-201.

TIJOLINHO VERMELHO, Disponível em

<https://pelamoradia.wordpress.com/2013/05/15/mocao-contra-despejo-de-200-familias-daocupacao-tijolinho-vermelho-em-joao-pessoa-pb/> acesso em 07 de jul. de 2015.

VIOLA, Solon Eduardo Annes. Direitos Humanos e Democracia no Brasil. São Leopoldo: Ed. UNISINOS, 2008.

WAISELFISZ, Julio Jacobo. Mapa da Violência 2014: os jovens do Brasil. Disponível em:<http://www.mapadaviolencia.org.br/pdf2014/Mapa2014_JovensBrasil_Preliminar.pdf > acesso em: 07 de jul. 2015.

WOLKMER, Antonio Carlos. Novos pressupostos para a temática dos Direitos Humanos. In: RUBIO, David Sanchez; FLORES, Joaquin Herrera; CARVALHO, Salo de. (Orgs.). Direitos humanos e globalização: fundamentos e possibilidades desde a teoria crítica, 2. ed., Porto Alegre: EDIPUCRS, 2010.

ZIZEK, Slavoj. Contra os Direitos Humanos. Tradução: Sávio Cavalcante. In: Mediações, Londrina, v. 15, n.1, p. 11-29, Jan/Jun. 2010.

O espectro da ideologia. In: ZIZEK, Slavoj. Um mapa da Ideologia. Tradução:Vera Ribeiro. Rio de Janeiro: Contraponto, 1996. 